\title{
Papers
}

\section{Randomised trials of secondary prevention programmes in coronary heart disease: systematic review}

Finlay A McAlister, Fiona M E Lawson, Koon K Teo, Paul W Armstrong

\begin{abstract}
Objective To determine whether multidisciplinary disease management programmes for patients with coronary heart disease improve processes of care and reduce morbidity and mortality.

Data sources Randomised clinical trials of disease management programmes in patients with coronary heart disease were identified by searching Medline 1966-2000, Embase 1980-99, CINAHL 1982-99, SIGLE 1980-99, the Cochrane controlled trial register, the Cochrane effective practice and organisation of care study register, and bibliographies of published studies.

Data extraction Studies were selected and data were extracted independently by two investigators, and summary risk ratios were calculated by using both the random effects model and the fixed effects model.
\end{abstract}

Data synthesis A total of 12 trials (9803 patients with coronary heart disease) were identified. Disease management programmes had positive impacts on processes of care. Patients randomised to these programmes were more likely to be prescribed efficacious drugs (risk ratio 2.14 (95\% confidence interval 1.92 to 2.38 ) for lipid lowering drugs, 1.19 (1.07 to 1.32) for $\beta$ blockers, and 1.07 (1.03 to 1.11) for antiplatelet agents). Five out of seven trials evaluating risk factor profiles showed significantly greater improvements with these programmes in comparison with usual care (with effect sizes in the moderate range). Summary risk ratios were $0.91(0.79$ to 1.04 ) for all cause mortality, 0.94 (0.80 to 1.10$)$ for recurrent myocardial infarction, and 0.84 (0.76 to 0.94) for admission to hospital. Five of the eight trials evaluating quality of life or functional status reported better outcomes in the intervention arms. Only three of these trials reported the costs of the intervention-the interventions were cost saving in two cases.

Conclusions Disease management programmes improve processes of care, reduce admissions to hospital, and enhance quality of life or functional status in patients with coronary heart disease. The programmes' impact on survival and recurrent infarctions, their cost effectiveness, and the optimal mix of components remain uncertain.

\section{Introduction}

Coronary heart disease is already the major cause of illness and death in Western countries. The size of this epidemic is likely to increase-populations are ageing, and advances in treatment lead to an increasing number of survivors of myocardial infarction. ${ }^{1}$ Despite many interventions that have been proved to reduce recurrence of myocardial infarction, audits of practice consistently reveal suboptimal control of cardiovascular risk factors and underuse of antiplatelet agents, $\beta$ blockers, and lipid lowering drugs in patients with coronary heart disease. ${ }^{2}$

Disease management programmes are increasingly advocated as a means of improving management of and outcomes for patients with coronary heart disease. ${ }^{3-5}$ Disease management has been defined as "a combination of patient education, provider use of practice guidelines, appropriate consultation, and supplies of drugs and ancillary services." Although the specific elements of these programmes vary across different settings and disease states, great enthusiasm exists for coronary heart disease management programmes that use multidisciplinary teams and specialised clinics dedicated to the prevention of death or of recurrent myocardial infarction. ${ }^{4}$

Despite this enthusiasm the effectiveness of these programmes in reducing morbidity and mortality is largely unknown. Many reviews have shown that cardiac rehabilitation programmes improve outcomes in survivors of myocardial infarction, ${ }^{6-8}$ but these conclusions are based largely on eight trials that tested exercise programmes of varying intensity. Only two of the trials included in these reviews evaluated disease management approaches, and neither of these trials found a benefit from the intervention. Most subsequent studies of multidisciplinary disease management programmes have been uncontrolled before-after case series, and the results of the few randomised trials that have been done are far from conclusive owing to inadequate power. In the absence of a conclusive trial, the data should be examined in a systematic way in an attempt to draw valid conclusions. We thus performed a rigorous systematic review of randomised trials to determine whether multidisciplinary disease management programmes improve processes of care and reduce morbidity and mortality in patients with established coronary heart disease.

\author{
Division of General \\ Internal Medicine, \\ 2E3.24 WMC, \\ University of \\ Alberta Hospital, \\ 8440112 Street, \\ Edmonton, AL, \\ Canada T6G 2R7 \\ Finlay A McAlister \\ assistant professor \\ Division of Geriatric \\ Medicine, \\ University of \\ Alberta, Edmonton, \\ AL, Canada \\ T6G 2R7 \\ Fiona M E Lawson \\ assistant clinical \\ professor \\ Division of \\ Cardiology, \\ University of \\ Alberta \\ Paul W Armstrong \\ professor \\ Division of \\ Cardiology, \\ McMaster \\ University, \\ Hamilton, $\mathrm{ON}$, \\ Canada L8S 418 \\ Koon K Teo \\ professor \\ Correspondence to: \\ F McAlister \\ Finlay.McAlister@ \\ ualberta.ca
}

BMJ 2001;323:957-62 


\section{Methods}

Searching for relevant studies

We searched electronic databases (Medline 1966-2000, Embase 1980-99, CINAHL 1982-99, SIGLE 1980-99, the Cochrane controlled trial register, and the Cochrane effective practice and organisation of care study register) for randomised trials in humans; no language restrictions were applied. We used the following textword terms and MeSH headings: case management (exp), comprehensive health care (exp), disease management (exp), health services research (exp), home care services (exp), clinical protocols (exp), patient care planning (exp), quality of health care (exp), rehabilitation, nurse led clinics, special clinics, and myocardial ischemia (exp). To identify any studies missed by the literature searches, we hand searched the bibliographies of all identified studies and contacted experts on the subject.

\section{Selection of studies and abstraction of data}

Two of the investigators (FM and FL) independently reviewed the titles and abstracts of all citations to identify any studies reporting the impact of disease management programmes on death, myocardial infarction, or rates of admission to hospital in patients with coronary heart disease (clinically manifest as angina, myocardial infarction, or coronary revascularisation). Both investigators used pre-standardised data abstraction forms to review the full texts of all potentially relevant articles. Any discrepancies were resolved by consensus. Outcomes were assigned according to the intention to treat principle. We contacted original investigators where necessary to clarify the published data.

We excluded studies if they were not randomised, were primary prevention studies, evaluated single modality interventions (such as exercise programmes or telephone follow up), tested inpatient interventions, or enrolled fewer than 50 participants. We included studies in which patients with multiple diseases were enrolled if the outcomes for patients with coronary heart disease were reported separately or if these patients comprised at least half of the study participants.

\section{Statistical analysis}

We used the Meta-Analyst 0.998 software (J Lau, New England Medical Center, Boston, MA) to perform analyses. As the primary outcomes were relatively common, we calculated risk ratios and used Cochran's $\mathrm{Q}$ test to assess heterogeneity in each outcome of interest. We combined studies by using both the DerSimonian and Laird random effects model and the Mantel-Haenszel-Peto fixed effects model; as these models gave similar results for all analyses, we report only the fixed effects results here. To standardise the reporting of results for non-dichotomous outcomes (such as change in cholesterol concentrations, blood pressure, or scores for quality of life or functional status), we used the effect size technique described by Kazis et al. ${ }^{9}$ We calculated the effect size by dividing the absolute difference between intervention and control arms by the standard deviation in the control arms. By convention, effect sizes $<0.20$ are considered trivially small, 0.50 is moderate, and $>0.80$ is large. We conducted sensitivity analyses, defined in advance, to look at the effects on the summary risk ratios of quality of study, duration of intervention, length of follow up, year of study completion, and elements of the disease management programme.

\section{Results}

\section{Study selection and evaluation}

Of the 1562 citations originally identified in our search, we retrieved 72 that seemed potentially relevant. We excluded 55 of these studies after detailed evaluation: 16 were not randomised, 13 were primary prevention studies, eight did not report the primary outcomes, eight evaluated interventions that were not comprehensive disease management systems (such as exercise therapy alone), five did not report the outcomes for patients with coronary heart disease separately or included $<50 \%$ patients with coronary heart disease, two tested an inpatient based intervention, two enrolled fewer than 50 patients, and one had flawed methods (patients excluded after randomisation). (A full list of excluded studies is available from FM on request.) Our search retrieved 10 trials not included in previous systematic reviews.

Disagreement among the reviewers (FM and FL) regarding eligibility of the studies occurred on four occasions, for a $\kappa$ value of 0.85 . All disagreements were resolved by consensus.

Of the randomised trials eligible for inclusion, three were reported in more than one publication. One trial reported different end points in two separate publications. ${ }^{10} 11$ One trial reported the outcomes for all patients enrolled (only $45 \%$ of whom had heart disease) and, in a separate publication, provided details of event rates in the subgroup of patients with heart disease. $^{12}$ The World Health Organization trial included 24 collaborating centres, but the original investigators excluded seven sites because of poor follow up of participants and four sites because of significant differences at baseline between the intervention and control arms. ${ }^{14}$ We included the three year outcome data from the remaining 13 sites as one trial for the purposes of this analysis, an approach validated by the non-significant tests for statistical heterogeneity for all cause mortality $(\mathrm{Q}=15.7,11 \mathrm{df}, \mathrm{P}=0.16)$ and myocardial infarction $(\mathrm{Q}=15.9,11 \mathrm{df}, \mathrm{P}=0.15)$ and the fact that the summary risk ratios for both end points were identical under the random and fixed effects models. Although the two Finnish centres in the WHO trial published their results separately (and for multiple periods of follow up), we included only their three year outcome data with the other 11 WHO sites for consistency of data presentation. ${ }^{15-17}$

\section{Studies included}

Table 1 presents summary data from the 12 randomised trials eligible for this systematic review. In all of the trials, patients randomised to the control groups received usual care (this was generally undefined).

\section{Quantitative data synthesis}

Reinfarction rate-None of the seven trials reporting this end point detected a significant difference between patients in intervention and control arms (fig 1), and the summary risk ratio for all 7480 patients was 0.94 (95\% confidence interval 0.80 to 1.10 ). 
Table 1 Studies included in analysis of secondary prevention programmes in coronary heart disease

\begin{tabular}{|c|c|c|c|c|c|c|}
\hline Study & $\begin{array}{l}\text { Sample } \\
\text { size }\end{array}$ & Study population (location) & $\begin{array}{l}\text { Mean age } \\
\text { (years) }\end{array}$ & $\%$ men & Key components of intervention & $\begin{array}{r}\text { Duration of } \\
\text { intervention } \\
\text { (months) }\end{array}$ \\
\hline $\begin{array}{l}\text { Vermeulen et al } \\
(1983)^{18}\end{array}$ & 98 & $\begin{array}{l}\text { Men } 40-55 \text { years, discharged after AMI } \\
\text { (Netherlands) }\end{array}$ & 49 & 100 & $\begin{array}{l}\text { Multidisciplinary team (details not given) involved in exercise } \\
\text { rehabilitation and social and psychological support for patients }\end{array}$ & $1.5-2$ \\
\hline $\begin{array}{l}\text { World Health } \\
\text { Organization* } \\
(1983)^{14}\end{array}$ & 1735 & $\begin{array}{l}\text { Men }<65 \text { years, discharged after AMI } \\
\text { (Europe) }\end{array}$ & 53 & 100 & $\begin{array}{l}\text { Multidisciplinary team (components differed at each centre) } \\
\text { involved in health education and supervised exercise } \\
\text { programme for patients }\end{array}$ & 36 \\
\hline SCRIP $(1994)^{19}$ & 300 & $\begin{array}{l}\text { Patients }<75 \text { years referred for } \\
\text { angiography for CHD (United States) }\end{array}$ & 56 & 86 & $\begin{array}{l}\text { Nurse managed patient education and algorithm driven } \\
\text { management of risk factors, exercise programme, frequent } \\
\text { telephone and clinic visits with nurse }\end{array}$ & 48 \\
\hline $\begin{array}{l}\text { DeBusk et al } \\
(1994)^{20}\end{array}$ & 585 & $\begin{array}{l}\text { Patients } \leqslant 70 \text { years discharged after AMI } \\
\text { (United States) }\end{array}$ & 57 & 79 & $\begin{array}{l}\text { Nurse managed patient education and counselling, exercise } \\
\text { programme, frequent telephone contact, and algorithm based } \\
\text { lipid therapy }\end{array}$ & 12 \\
\hline $\begin{array}{l}\text { Cupples et al } \\
(1994)^{21}\end{array}$ & 688 & $\begin{array}{l}\text { Patients }<75 \text { years with angina for } \\
\geqslant 6 \text { months, identified from general } \\
\text { practice records (United Kingdom) }\end{array}$ & 63 & 59 & Nurse directed patient education and counselling & 24 \\
\hline $\begin{array}{l}\text { Jones et al } \\
(1996)^{22}\end{array}$ & 2328 & $\begin{array}{l}\text { Patients discharged home within } 28 \text { days } \\
\text { of AMI (United Kingdom) }\end{array}$ & 62 & 73 & $\begin{array}{l}\text { Nurse and psychologist regularly saw participants for } \\
\text { education, counselling, and relaxation or stress management } \\
\text { training }\end{array}$ & 1.75 \\
\hline M-HART $(1997)^{23}$ & 1376 & Patients discharged after AMI (Canada) & 59 & 66 & $\begin{array}{l}\text { Nurse contacted patients monthly by telephone, providing } \\
\text { education and advice and screening patients for psychological } \\
\text { distress; nurses referred patients to other healthcare resources } \\
\text { as needed }\end{array}$ & 12 \\
\hline $\begin{array}{l}\text { Campbell et al } \\
(1998)^{10}\end{array}$ & 1343 & $\begin{array}{l}\text { Patients }<80 \text { years with documented } \mathrm{CHD} \\
\text { recruited from general practice records } \\
\text { (United Kingdom) }\end{array}$ & 66 & 58 & $\begin{array}{l}\text { Regular follow up at secondary prevention clinics run by } \\
\text { nurses, promoting medical and lifestyle approaches to } \\
\text { prevention }\end{array}$ & 12 \\
\hline SHIP $(1999)^{24}$ & 597 & $\begin{array}{l}\text { Patients with AMI or recent onset angina } \\
\text { discharged from hospital or seen in a } \\
\text { chest pain clinic (United Kingdom) }\end{array}$ & 64 & 71 & $\begin{array}{l}\text { Cardiac liaison nurse coordinated care between discharging } \\
\text { service and family physician; patients given personal health } \\
\text { record and prompts for follow up }\end{array}$ & 12 \\
\hline $\begin{array}{l}\text { Fitzgerald et al } \\
(1994)^{25}\end{array}$ & $\begin{array}{l}668(2 / 3 \text { with } \\
\text { heart disease) }\end{array}$ & $\begin{array}{l}\text { Patients }>45 \text { years discharged from a } \\
\text { general medicine inpatient service and } \\
\text { being followed at the general medicine } \\
\text { clinic of a Veterans Administration hospital } \\
\text { (United States) }\end{array}$ & 65 & 100 & $\begin{array}{l}\text { Nurse managed patient education, coordination of care, } \\
\text { frequent telephone contact, and protocol driven systematic } \\
\text { assessments for unmet sociomedical needs }\end{array}$ & 12 \\
\hline $\begin{array}{l}\text { Naylor et al } \\
(1994)^{26}\end{array}$ & $\begin{array}{l}276 \text { (142 with } \\
\text { CHD or CHF) }\end{array}$ & $\begin{array}{l}\text { Patients }>70 \text { years admitted to a tertiary } \\
\text { care hospital with either CHD or CHF } \\
\text { (United States) }\end{array}$ & 76 & 49 & $\begin{array}{l}\text { Comprehensive discharge planning protocol with gerontological } \\
\text { nurse providing education, coordinating care, and maintaining } \\
\text { telephone contact for } 2 \text { weeks }\end{array}$ & 0.5 \\
\hline
\end{tabular}

$\mathrm{AMI}=$ acute myocardial infarction; $\mathrm{CHD}=$ coronary heart disease; $\mathrm{CHF}=$ congestive heart failure.

${ }^{*}$ The results for 13 of the 24 collaborating centres in the World Health Organization trial are included here. Reasons for the exclusion of the other 11 centres are given in the text.

All cause mortality-Only one out of 10 trials reported a significant survival benefit with the intervention (fig 2). The summary risk ratio of 0.91 (0.79 to 1.04 ) for all 10 trials (9718 patients) confirms that these interventions have not been shown to improve survival.

Rate of admission to hospital-Although only two ${ }^{10} 19$ of the six trials reporting admission rates ${ }^{10} 1319232526$ found a significant difference, the summary risk ratio of 0.84 (0.76 to 0.94$)$ is consistent with a beneficial impact of the interventions. Of the four trials that evaluated length of stay, two showed shorter lengths of stay or a reduced total of days in hospital in the intervention group. ${ }^{1326}$ Furthermore, one trial reported that significantly fewer patients in the intervention arms had multiple readmissions. ${ }^{13}$ There was insufficient detail in these studies to permit analysis by type of admission (for example, cardiac $v$ non-cardiac).

Sensitivity analyses-Year of study completion, duration of intervention, and length of follow up had no effect on the observed results (data not shown). Because of the small number of trials and the poor reporting of the specific elements of the intervention in many of the trials, analyses by different components of the multidisciplinary interventions failed to detect any one component that was statistically beneficial, although there was a trend towards greater survival benefits in those programmes that included structured exercise (risk ratio $0.87(0.71$ to 1.05$) v 0.94$ (0.78 to 1.13)).

Processes of care-Seven trials tested the impact of the disease management programmes on cardiovascular risk factors; five showed significantly greater improvements in patients randomised to the interventions, although the effect sizes were generally small to moderate (table 2). Of the seven trials that assessed the use of drugs proved to be efficacious, all but two showed significantly increased prescription of at least one of these treatments in the intervention group. Pooled data showed that patients in the

\begin{tabular}{lccc}
\hline Study & Treatment & Control & Odds ratio (95\% Cl) \\
Vermeulen $^{18}$ & $4 / 47$ & $9 / 51$ & $0.48(0.16$ to 1.46$)$ \\
WHO $^{14}$ & $150 / 893$ & $139 / 842$ & $1.02(0.82$ to 1.26$)$ \\
SCRIP $^{19}$ & $6 / 145$ & $11 / 155$ & $0.58(0.22$ to 1.54$)$ \\
DeBusk $^{20}$ & $21 / 293$ & $29 / 292$ & $0.72(0.42$ to 1.24$)$ \\
Jones $^{22}$ & $43 / 1168$ & $48 / 1160$ & $0.89(0.59$ to 1.33$)$ \\
M-HART $^{23}$ & $44 / 692$ & $42 / 684$ & $1.04(0.69$ to 1.56$)$ \\
Campbell $^{10}$ & $13 / 540$ & $12 / 518$ & $1.04(0.48$ to 2.26$)$ \\
Overall $^{12}$ & $281 / 3778$ & $290 / 3702$ & $0.94(0.8$ to 1.1$)$
\end{tabular}

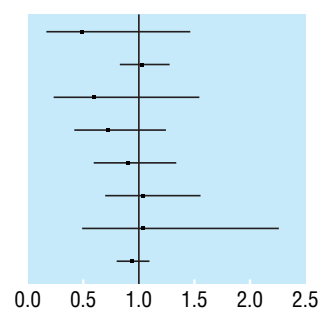

Fig 1 Impact of interventions on recurrent myocardial infarctions. Data for all trials except that of Campbell et $\mathrm{al}^{10}$ are for the combined end point of non-fatal and fatal myocardial infarction. Campbell et al collected data only on non-fatal reinfarction rate and total mortality and were unable to define causes of mortality at time of contact with FM 


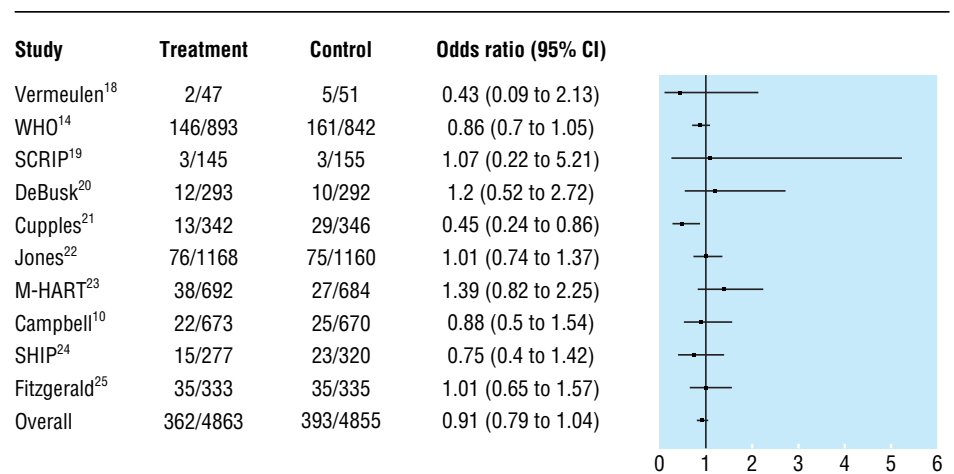

Fig 2 Impact of interventions on all cause mortality

intervention arm were more likely to be prescribed these treatments, with risk ratios of 2.14 (1.92 to 2.38) for lipid lowering drugs, 1.19 (1.07 to 1.32) for $\beta$ blockers, and 1.07 (1.03 to 1.11) for antiplatelet agents. The increases in prescription of $\beta$ blockers and antiplatelet agents are noteworthy, as these trials tested interventions designed largely to look at lipid lowering in patients with coronary heart disease.

Other end points-Five of the eight trials evaluating quality of life or functional status showed better scores in the intervention arms, although these were generally small and achieved significance in only three studies (table 2). Only three of these trials described the costs of the intervention. ${ }^{12}{ }^{20}{ }^{26}$ Two reported that their inter- vention was cost saving, ${ }^{126}$ but none performed formal cost effectiveness analyses.

\section{Discussion}

The weight of the evidence from randomised controlled trials shows that comprehensive disease management programmes have a positive impact on processes of care (risk factor profiles, prescription of proved efficacious drugs) that are closely linked to subsequent morbidity and mortality in patients with coronary heart disease. ${ }^{28}$ Although these trials failed to document any convincing survival benefit or reduction in recurrent myocardial infarctions, there was a significant reduction in admissions to hospital and a trend towards improved symptom scores, exercise tolerance, or quality of life with these programmes.

\section{Lack of survival benefit}

Previously published systematic reviews of cardiac rehabilitation in survivors of myocardial infarction have shown survival benefits in the order of $20-24 \%{ }^{6-8}$ However, most of the trials included in those overviews evaluated interventions that were primarily based on exercise (and thus not included in our overview). ${ }^{6-8}$ As activity levels are inversely proportional to cardiovascular mortality, and exercise training confers substantial physiological and clinical benefits, ${ }^{29}$ it is not surprising that those trials found greater treatment effects than did trials evaluating multidisciplinary interventions that were not primarily exercise based. Although too few trials in this overview included struc-

Table 2 Impact of interventions on other end points

\begin{tabular}{|c|c|c|c|c|c|c|c|c|}
\hline \multirow[b]{2}{*}{ Study } & \multicolumn{3}{|c|}{ Major cardiovascular risk factors } & \multicolumn{3}{|c|}{ Use of proved efficacious therapies } & \multirow[b]{2}{*}{$\begin{array}{l}\text { Quality of life } \\
\text { (effect sizes) }\end{array}$} & \multirow[b]{2}{*}{$\begin{array}{l}\text { Deterioration in functional } \\
\text { status or symptom scores }\end{array}$} \\
\hline & $\begin{array}{l}\text { Reduction in } \\
\text { cholesterol } \\
\text { concentration } \\
\text { (effect sizes) }\end{array}$ & $\begin{array}{l}\text { Rates of } \\
\text { smoking } \\
\text { cessation }\end{array}$ & $\begin{array}{l}\text { Reduction in } \\
\text { blood pressure } \\
\text { (effect sizes) }\end{array}$ & $\begin{array}{c}\text { Antiplatelet } \\
\text { agents }\end{array}$ & $\beta$ blockers & $\begin{array}{l}\text { Lipid lowering } \\
\text { drugs }\end{array}$ & & \\
\hline Vermeulen et al $1^{18}$ & $0.4^{*}$ & $59 \% \vee 60 \%$ & $\mathrm{NR}$ & NR & NR & $\mathrm{NR}$ & NR & $\begin{array}{c}21 \% \text { v } 48 \% \text { had } \\
\text { progressive angina* }\end{array}$ \\
\hline $\mathrm{WHO}^{14}$ & $0.6^{*}$ & $50 \% \vee 42 \%$ & $0.4^{\star}$ & NR & $44 \% \vee 29 \%^{*}$ & $28 \% \vee 11 \%^{*}$ & NR & $69 \% \vee 66 \%$ had angina \\
\hline $\mathrm{SCRIP}^{19}$ & $1.3^{*}$ & $0 \% \vee 0 \%$ & $0.4^{\star}$ & $76 \%$ v $76 \%$ & $26 \% \vee 26 \%$ & $93 \% \vee 30 \%^{*}$ & NR & NR \\
\hline DeBusk et al ${ }^{20}$ & $0.6^{*}$ & $70 \%$ v $53 \%{ }^{*}$ & NR & NR & NR & $66 \%$ v $21 \%^{*}$ & NR & NR \\
\hline Cupples et $\mathrm{al}^{21}$ & 0.02 & $22 \%$ v $17 \%$ & $(0.02)$ & NR & $53 \% \vee 40 \% *$ & NR & NR & NR \\
\hline Jones et al ${ }^{22}$ & NR & NR & NR & $75 \%$ v $75 \%$ & $31 \% \vee 31 \%$ & NR & $\begin{array}{c}\text { No difference from } \\
\text { baseline in either group }\end{array}$ & $\begin{array}{l}\text { Less frequent anginal } \\
\text { episodes in intervention } \\
\text { arm }(3 \vee 4 \text { per week })^{\star}\end{array}$ \\
\hline$\overline{M-H A R T^{23}}$ & NR & NR & NR & NR & NR & NR & $\begin{array}{c}0.07 \text { on Beck depression } \\
\text { inventory }\end{array}$ & NR \\
\hline Campbell et al ${ }^{10}{ }^{11} \ddagger$ & Odds ratio $2.6^{*}$ & $1 \% \vee 11 \%$ & Odds ratio $2.5^{*}$ & $81 \% \vee 66 \%{ }^{*}$ & NR & $41 \%$ v $22 \%^{*}$ & $\begin{array}{l}\text { All but mental and } \\
\text { energy subsets of SF-36 } \\
\text { better in intervention } \\
\text { arms }(0.10-0.21)^{\star}\end{array}$ & $\begin{array}{c}7 \% \vee 11 \% \text { had worsening } \\
\text { angina }\end{array}$ \\
\hline Fitzgerald et all ${ }^{25}$ & NR & NR & NR & NR & NR & NR & NR & NR \\
\hline Naylor et al $(1994)^{26}$ & NR & NR & NR & NR & NR & NR & $\begin{array}{l}\text { No difference from } \\
\text { baseline in either group } \\
\text { on enforced social } \\
\text { dependency scale }\end{array}$ & $\begin{array}{c}\text { No difference from } \\
\text { baseline in either group on } \\
\text { enforced social } \\
\text { dependency scale }\end{array}$ \\
\hline Naylor et al $(1999)^{13}$ & NR & NR & NR & NR & NR & NR & $\mathrm{NR}$ & $\begin{array}{c}2.3 \vee 1.8 \text { improvement on } \\
\text { a } 51 \text { point scale (enforced } \\
\text { social dependency scale) }\end{array}$ \\
\hline$\overline{\text { SHIP }^{24}}$ & 0.11 & $19 \%$ v $20 \%$ & 0.10 & $87 \%$ v $85 \%$ & NR & $30 \%$ v $29 \%$ & (0.05) on EuroQol score & $\begin{array}{l}2.4 \vee 2.2 \text { on a } 10 \text { point } \\
\text { scale assessing } \\
\text { interference with activity }\end{array}$ \\
\hline
\end{tabular}

Effect sizes for reductions in cholesterol concentration and blood pressure and differences in quality of life were determined by dividing the direct increment between groups by the standard deviation in the control group (see text for further explanation). Effect sizes expressed as intervention $v$ control group; thus positive values imply greater risk factor reduction or higher quality of life scores in intervention patients; values in parentheses represent greater risk factor reduction or higher quality of life scores in control patients.

NR=not measured or not reported.

${ }^{*}$ Significant difference $(\mathrm{P}<0.05)$ between intervention and control patients.

†Assessed with a previously validated scale for support, anxiety, and depression (DSSI/SAD). ${ }^{27}$

fln this study, cholesterol and blood pressure reductions were reported as odds ratios for achieving target values (values $>1$ signify that target values were more likely to be achieved in the intervention arm patients). 
tured exercise as part of the intervention to show a clearly beneficial treatment effect with this modality, a trend towards greater survival benefit was seen in programmes that included this element.

Why did these trials (including almost 10000 participants) not show a significant survival benefit? Firstly, these trials may have been too short (median follow up was 12 months) to show a clear impact on mortality. Secondly, the patients included in these studies were at sufficiently low risk that the likelihood of detecting a beneficial effect was remote-the event rates in the control groups in these trials were substantially lower than in other trials enrolling patients with clinically overt coronary heart disease.$^{30}$ Thirdly, the incremental benefit of disease management over usual care may be very small in the settings in which the trials were carried out (where management in the "usual care" arm may be close to optimal already). Indeed, disease management programmes are likely to be most beneficial in those settings where usual care is suboptimal. Finally, labelling patients as having one disease for a management programme may have led to suboptimal care for their comorbid conditions and, as a result, to no real difference in all cause mortality. ${ }^{31}$ Nevertheless, we believe that the clear improvements in risk factor profiles and prescription of lipid lowering drugs, $\beta$ blockers, and antiplatelet agents in patients exposed to these interventions will translate into clinically important reductions in recurrent myocardial infarctions and death.

\section{Limitations of the study}

As with all systematic reviews, this study has several potential limitations. The most obvious (the relatively small sample size, the lack of double blind studies, and our inability to identify unpublished studies) arise from the primary data. As these limitations tend to result in overestimation of any treatment effects, ${ }^{32}$ these limitations in fact strengthen our conclusions about the lack of convincing evidence that coronary heart disease management programmes reduce total mortality or recurrent myocardial infarctions. On the other hand, our interpretation of these trials and the generalisability of the programmes described is hampered by the imprecise descriptions of the interventions and the lack of data to determine the incremental benefits of the various components of each intervention.

Although some people may criticise our choice of primary end points as being too broad to detect differences in "cardiac" morbidity and mortality, we believe that it is most appropriate to look at all cause mortality or admission to hospital, as interventions to reduce use of resources in one area can have unanticipated effects in another. Finally, owing to the paucity of data, we are unable to make a definitive comment on the cost effectiveness and economic impact of the programmes tested in these trials.

\section{Conclusions}

Although the interventions that were offered varied substantially and the studies often enrolled highly selected populations, multidisciplinary disease management programmes (particularly those that include a structured exercise component) for secondary prevention in patients with coronary heart disease do seem to have a beneficial impact.

\section{What is already known on this topic}

Evidence based cardiac rehabilitation programmes of varying intensity improve morbidity and mortality in survivors of myocardial infarction

Patients with coronary heart disease are increasingly referred to multidisciplinary clinics that use disease management approaches

\section{What this study adds}

Disease management approaches have a positive impact on processes of care (prescription of proved efficacious drugs and cardiovascular risk profiles of patients)

Most of the trials reported that quality of life or functional status was better in patients treated with disease management rather than usual care

The optimal mix of components and the cost effectiveness of these programmes is still uncertain

Several questions remain to be answered. In particular, the optimal mix of interventions, their frequency and duration, and their cost effectiveness are still unclear. Furthermore, the lack of convincing evidence of any survival benefit means that the developers of disease management programmes for coronary heart disease should include rigorous evaluations of long term outcomes to confirm that the intended benefits have been attained.

We acknowledge the help of Dr N C Campbell (references 10 and 11), Dr R West (reference 22), and Dr M Naylor (references 12 and 26) in providing further details about their studies.

Contributors: FAMcA conceived and designed the study, collected and analysed the data, drafted the paper (and subsequent revisions), and is the guarantor. FMEL assisted with the design of the study, the collection of data, and critical revisions of the paper. KKT and PWA assisted with the design of the study and critical revisions of the paper.

Funding: FAMcA is a population health investigator of the Alberta Heritage Foundation for Medical Research.

Competing interests: PWA has consulted for Pfizer and received a research grant from Novartis in the past five years.

1 Bonneux L, Barendregt JJ, Meeter K, Bonsel GJ, van der Maas PJ. Estimating clinical morbidity due to ischemic heart disease and congestive hear failure: the future rise of heart failure. Am J Public Health 1994;84:20-8.

2 EUROASPIRE I and II Group. Clinical reality of coronary prevention guidelines: a comparison of EUROASPIRE I and II in nine countries. Lancet 2001:357:995-1001.

3 Hunter DJ, Fairfield G. Disease management. BMJ 1997;315:50-3.

4 Greenland P. Closing the treatment gap: in the community and at hospital discharge. Am J Med 1996;101(suppl 4A):76-78S

5 Cohen JD. ABCs of secondary prevention of CHD: easier said than done Lancet 2001;357:972-3.

6 O'Connor GT, Buring JE, Yusuf S, Goldhaber SZ, Olmstead EM, Paffenbarger RS, et al. An overview of randomized trials of rehabilitation with exercise after myocardial infarction. Circulation 1989:80:234-44.

7 Oldridge NB, Guyatt GH, Fischer ME, Rimm AA. Cardiac rehabilitation after myocardial infarction. Combined experience of randomized clinical trials. JAMA 1988;260:945-50.

8 Dinnes J, Kleijnen J, Leitner M, Thompson D. Cardiac rehabilitation. Qual Health Care 1999;8:65-71.

9 Kazis LE, Anderson JJ, Meenan RF. Effect sizes for interpreting changes in health status. Med Care 1989:27:S178-89.

10 Campbell NC, Thain J, Deans HG, Ritchie LD, Rawles JG, Squair JL. Secondary prevention clinics for coronary heart disease: randomised trial of effect on health. BMJ 1998;316:1434-7.

11 Campbell NC, Ritchie LD, Thain J, Deans HG, Rawles JG, Squair JL. Sec ondary prevention in coronary heart disease: a randomised trial of nurse led clinics in primary care. Heart 1998;80:447-52.

12 Naylor MD, Brooten D, Campbell R, Jacobsen BS, Mezey MD, Pauly MV et al. Comprehensive discharge planning and home follow-up of hospitalized elders. A randomized clinical trial. JAMA 1999;281:613-20. 
13 Naylor MD, McCauley KM. The effects of a discharge planning and home follow-up intervention on elders hospitalized with common medical and surgical cardiac conditions. J Cardiovasc Nurs 1999;14:44-54.

14 World Health Organization. Rehabilitation and comprehensive secondary prevention after acute myocardial infarction. Copenhagen: WHO, 1983:1-99. (WHO report 84.)

15 Kallio V, Hamalainen H, Hakkila J, Luurila OJ. Reduction in sudden deaths by a multifactorial intervention programme after acute myocardial infarction. Lancet 1979;ii: 1091-4

16 Hamalainen H, Luurila OJ, Kallio V, Knuts L-R, Arstila M, Hakkila J. Long-term reduction in sudden deaths after a multifactorial intervention programme in patients with myocardial infarction: 10-year results of a controlled investigation. Eur Heart J 1989;10:55-62.

17 Hamalainen H, Luurila OJ, Kallio V, Knuts L-R. Reduction in sudden deaths and coronary mortality in myocardial infarction patients after rehabilitation. Eur Heart J 1995;16:1839-44.

18 Vermeulen A, Lie KI, Durrer D. Effects of cardiac rehabilitation after myocardial infarction: changes in coronary risk factors and long-term prognosis. Am Heart J 1983; 105:798-801.

19 Haskell WL, Alderman EL, Fair JM, Maron DJ, Mackey SF, Superko R, et al. Effects of intensive multiple risk factor reduction on coronary atherosclerosis and clinical cardiac events in men and women with coronary artery disease. The Stanford coronary risk intervention project (SCRIP). artery disease. The Stanfor
Circulation 1994:89:975-90.

20 DeBusk RF, Houston Miller N, Superko R, Dennis CA, Thomas RJ, Lew HT, et al. A case-management system for coronary risk factor modification after acute myocardial infarction. Ann Intern Med 1994;120:721-9.

21 Cupples ME, McKnight A. Randomised controlled trial of health promotion in general practice for patients at high cardiovascular risk. $B M J$ 1994;309:993-6.

22 Jones DA, West RR. Psychological rehabilitation after myocardial infarction: multicentre randomised controlled trial. BMJ 1996;313:1517-21.
23 Frasure-Smith N, Lesperance F, Prince RH, Verrier P, Garber RA, Juneau $\mathrm{M}$, et al. Randomised trial of home-based psychosocial nursing intervention for patients recovering from myocardial infarction. Lancet 1997;350:473-9.

24 Jolly K, Bradley F, Sharp S, Smith H, Thompson S, Kinmonth AL, et al. Randomised controlled trial of follow up care in general practice of patients with myocardial infarction and angina: final results of the Southampton heart integrated care project (SHIP). BMJ 1999;318:706-11.

25 Fitzgerald JR, Smith DM, Martin DK, Freedman JA, Katz BP. A case manager intervention to reduce readmissions. Arch Intern Med 1994;154:1721-9.

26 Naylor M, Brooten D, Jones R, Lavizzo-Mourey R, Mezey M, Pauly M. Comprehensive discharge planning for the hospitalized elderly. Ann Intern Med 1994;120:999-1006.

27 Bedford A, Foulds GA, Sheffield BF. A new personal disturbance scale (DSSI-sAD). BrJ Soc Clin Psychol 1976;15:387-94.

28 Mant J, Hicks N. Detecting differences in quality of care: the sensitivity of measures of process and outcome in treating acute myocardial infarction. BMJ 1995;311:793-6.

29 Shephard RJ, Balady GJ. Exercise as cardiovascular therapy. Circulation 1999;99:963-72

30 Yusuf S, Wittes J, Friedman L. Overview of results of randomized clinical trials in heart disease. I. Treatments following myocardial infarction. JAMA 1988;260:2088-93.

31 Redelmeier DA, Tan SH, Booth GL. The treatment of unrelated disorders in patients with chronic medical diseases. N Engl J Med 1998;338:151620.

32 Schulz KF, Chalmers I, Hayes RJ, Altman DG. Empirical evidence of bias. JAMA 1995;273:408-12.

(Accepted 29 August 2001)
ELPS

The full version of this paper appears on bmj.com

\section{Influences on hospital admission for asthma in south Asian and white adults: qualitative interview study}

\author{
Chris Griffiths, Gurmit Kaur, Madeleine Gantley, Gene Feder, Sheila Hillier, Jill Goddard, \\ Geoff Packe
}

asthma care and were often south Asian. Patients with easy access described care suggesting partnerships with their general practitioner, had better confidence to control asthma, and were registered with practices with well developed asthma strategies that included policies for avoiding hospital admission.

Conclusions The different ways of coping with asthma exacerbations and accessing care may partly explain the increased risk of hospital admission in south Asian patients. Interventions that increase confidence to control asthma, confidence in the general practitioner, understanding of preventive treatment, and use of systemic corticosteroids in exacerbations may reduce hospital admissions. Development of more sophisticated asthma strategies by practices with better access and partnerships with patients may also achieve this.

\section{Introduction}

Black and south Asian people are at increased risk of hospital admission with asthma. ${ }^{1-7}$ No consistent differences in severity or prevalence of asthma, prescribed drugs, or asthma education have been described. ${ }^{148}$ In one study south Asian patients were less likely to report adherence to their drug regimen or self management behaviour. ${ }^{1}$ Interventions to reduce admission rates in black and Asian groups have met with variable success. ${ }^{9-11}$ 